Volume 16 - Número 1 - jan/jul de 2021

\title{
UMA ANÁLISE DOS MECANISMOS DE CONCEPTUALIZAÇÃO DO VERBO “CAIR" EM DADOS MULTIMODAIS
}

\section{AN ANALYSIS OF THE CONCEPTUALIZATION MECHANISMS OF THE VERB “TO FALL" IN MULTIMODAL DATA}

\author{
Hayat Passos ${ }^{1}$ \\ André Lisboa ${ }^{2}$ \\ Beatriz Graça ${ }^{3}$ \\ Maíra Avelar ${ }^{4}$
}

\begin{abstract}
RESUMO: O objetivo deste trabalho é analisar seis ocorrências do verbo "cair" abrigadas no Distributed Little Red Hen Lab, uma biblioteca de dados multimodais, a fim de descrever diferentes Modos de Representação e Esquemas Imagéticos corporificados nos gestos. Para isso, do ponto de vista teórico, recorremos às noções de Esquema Verbal, Modelos Cognitivos Idealizados, Frames, Esquemas Imagéticos, Construal, subjetividade e intersubjetividade. Além dessas noções, também abordamos a inter-relação entre metáforas e gestos; e, posteriormente, discutimos a respeito dos Modos de Representação Gestual. Do ponto de vista metodológico, desenvolvemos nossas análises baseando-nos no Sistema Linguístico de Notação Gestual (LASG), proposto por Bressem e colaboradoras (2013) e nas Orientações para a Análise de Metáforas nos Gestos (MIG-G), propostas por Cienki (2017). Foram selecionadas para análise seis ocorrências do verbo "cair", a partir do critério de categorização "mais metafóricas" ou "menos prototípicas", sendo que cada ocorrência funcionou de forma distinta: elas apresentaram diferentes Modos de Representação: "Holding/Molding (Segurar/Moldar -3D)", "Enacting (Encenar)" e "Drawing" (Desenhar) e diferentes referentes físicos retratados no gesto: delimitar barreiras, objeto e desenhar um gráfico. Além disso, três ocorrências instanciaram nos gestos o Esquema Imagético TRAJETÓRIA, uma ocorrência instanciou o Esquema Imagético OBJETO e a metáfora conceptual "IDEIAS SÃO OBJETOS", correlacionada verbalmente a uma expressão idiomática com sentido metafórico. Outras duas ocorrências instanciaram a metáfora orientacional LESS IS DOWN ("MENOS É PARA BAIXO") e o Esquema Imagético TRAJETÓRIA.
\end{abstract}

PALAVRAS-CHAVE: Cair. Metáfora. Multimodalidade.

ABSTRACT: The aim of this paper is to analyze six occurrences of the verb "to fall" housed at the Distributed Little Red Hen Lab (a multimodal data library), to describe different Modes of Representation and Image Schemas embodied in gestures. For this purpose, from the theoretical point of view, we use the notions of Verbal Schema, Idealized Cognitive Models, Frames, Image Schemas, Construal, Subjectivity and Intersubjectivity. In addition, we also examine the interrelationship between metaphors and gestures and, afterwards, we discuss about Gesture Modes of Representation. From the methodological point of view, we develop our analyses based on the Linguistic Annotation System for Gesture (LASG), proposed by Bressem et al. (2013) and on the Metaphor Identification Guidelines for Gesture (MIG-G), proposed by Cienki (2017). The occurrences of the verb "to fall" were selected based on the criteria of being more metaphorical or less prototypical. Each occurrence worked in a different way: they presented different Modes of Representation: "Holding/Molding", "Enacting" and "Drawing" and different physical referents depicted in gesture: set boundaries, object and drawing a graphic. In addition, the occurrences three occurrences conveyed the Image Schema PATH, one conveyed the Image Schema OBJECT and the Conceptual Metaphor "IDEAS ARE OBJECTS" and a linguistic metaphor unfolded into a Conceptual Metaphor, the occurrences two of them conveyed the orientational metaphor "LESS IS DOWN" and the Image Schema PATH.

KEYWORDS: To fall. Metaphor. Multimodality.

\footnotetext{
${ }^{1}$ Doutoranda em Linguística pela Universidade Estadual do Sudoeste da Bahia - UESB /PPGLIN. E-mail: hayat.passos@gmail.com. ORCID: https://orcid.org/0000-0002-5454-7947.

${ }^{2}$ Doutorando em Linguística pela Universidade Estadual do Sudoeste da Bahia - UESB /PPGLIN. E-mail: euandrelisboa@gmail.com. ORCID: https://orcid.org/0000-0002-2906-3107.

${ }_{3}^{3}$ Doutoranda em Linguística pela Universidade Estadual do Sudoeste da Bahia - UESB /PPGLIN. E-mail: biafgss@gmail.com. ORCID: https://orcid.org/0000-0003-0097-0202.

${ }^{4}$ Doutora em Linguística e Língua Portuguesa pela Pontifícia Universidade Católica de Minas Gerais. Professora Titular da Universidade Estadual do Sudoeste da Bahia - UESB. E-mail: mairavelar@uesb.edu.br. ORCID: https://orcid.org/0000-0003-4907-6121.
} 
Volume 16 - Número 1 - jan/jul de 2021

\section{Introdução}

A Linguística Cognitiva adota uma perspectiva empirista no estudo da linguagem, alinhando-se a tradições psicológicas e filosóficas que enfatizam a experiência humana e a centralidade do corpo humano nessa experiência. Nessa perspectiva, de cognição corporificada, a investigação da mente humana não pode ser separada do corpo, de modo que a experiência, a cognição e a realidade são concebidas a partir de uma ancoragem corporal. De acordo com o quadro teórico de Gestos como Ação Simulada (GAS) (HOSTETTER e ALIBALI, 2008), teoria que se baseia na ideia de que simulações mentais de ações e estados perceptuais ativam as mesmas áreas neuronais que são usadas nas ações reais e percepção, os gestos promoveriam evidências para a cognição corporificada, pois eles derivam de ações simuladas e percepções.

Dentro dessa perspectiva, defendida pela Linguística Cognitiva e voltada ao estudo dos gestos na integração gesto-fala, na qual se insere a proposta desse artigo, discutiremos a respeito das noções teóricas de Modelos Cognitivos Idealizados, Frames, Esquemas Imagéticos, Construal, subjetividade e intersubjetividade, que, na perspectiva cognitiva, estariam envolvidas na conceptualização do sentido. Além dessas noções, também abordamos a interrelação entre metáforas e gestos e, por fim, discutiremos a respeito dos Modos de Representação gestual.

\section{A noção de esquema verbal na Gramática Cognitiva Langackeriana}

Langacker (2008) propõe que o esquema para verbos pressupõe duas habilidades cognitivas fundamentais: (i) a capacidade de apreender relações e (ii) traçar relações através do tempo. De acordo com autor, as relações podem ser apreendidas em múltiplos níveis de organização. Diante disso, podemos apreender relações simples (simplex), ou seja, constituídas por uma única configuração totalmente manifestada em um único ponto do tempo, ou relações que são complexas (complex), constituídas de relações entre múltiplos componentes, geralmente manifestadas sucessivamente por meio de um período de tempo contínuo. $\mathrm{O}$ autor exemplifica essas relações com um evento simples: uma bola rolando para baixo em uma inclinação. Para ele, esse evento se desenvolve através do tempo, pois em cada instante, a bola ocupa alguma posição no espaço, mas em cada caso, uma posição diferente. Coletivamente, essas posições definem o caminho espacial da bola. A situação obtida em cada momento constitui uma relação simples (simplex): uma única configuração na qual a bola ocupa uma localização específica. O evento global, por sua vez, inclui um número indefinido de relações como essas e, portanto, é complexo (complex).

O autor argumenta que, experimentalmente, a apreensão de um evento é similar a assistir uma imagem em movimento, em oposição ao exame de uma série de fotografias, uma vez que a concepção de um evento é contínua ao invés de discreta, mesmo que cada pedaço de tempo constitua uma relação simples (simplex). Essas relações componentes - referidas como estados - não são examinadas individualmente, nem separadamente no nível de percepção consciente. Ao invés disso, o evento é conceptualizado como integralmente desenvolvido.

Nessa continuidade integrada, segundo Langacker (2008), estados componentes de um evento (relações simples - simplex) são bastante análogos a "pedaços" constitutivos de um objeto físico. Essa não-repartição das entidades constitutivas resulta em objetos e eventos sendo percebidos como contínuos. Dessa forma, a percepção de continuidade implica algum tipo de operação mental que serve ao registro de uma ocorrência ininterrupta de entidades constitutivas através de sua extensão. $\mathrm{O}$ autor descreve esse processo como escaneamento, pelo qual os espaços constitutivos ou estados são integrados para criar uma concepção ininterrupta da 
Volume 16 - Número 1 - jan/jul de 2021

extensão temporal e espacial desse evento. Sendo assim, esse escaneamento, que ocorre com o evento, constitui nossa capacidade de traçar uma relação através do tempo.

\section{As noções de Modelos Cognitivos Idealizados, Frames, Esquemas Imagéticos, Construal,} Subjetividade e intersubjetividade

\subsection{Modelos cognitivos idealizados, frames e esquemas imagéticos}

Para Lakoff (1987), nosso conhecimento é organizado por meio de estruturas chamadas Modelos Cognitivos Idealizados (doravante, MCI). Segundo o autor, "cada MCI é um todo complexo estruturado, uma Gestalt que usa quatro tipos de estruturação: os mapeamentos proposicionais, os esquemas imagéticos, os metafóricos e os metonímicos". (LAKOFF, 1987, p.68). Para fundamentar o conceito de MCI, em um primeiro momento, o autor explica o conceito de frame, proposto por Fillmore (1975): "o termo frame designa um sistema estruturado de conhecimento, armazenado na memória de longo prazo e organizado a partir da esquematização da experiência".

Fillmore (1975) estabelece uma relação entre frames e protótipos. Para ele, "em alguns casos, a área de experiência na qual um frame linguístico se impõe é prototípica" (FILLMORE, 1975, p. 124) ${ }^{5}$. A ideia de Fillmore sobre frames prototípicos instancia o conceito de Modelos Cognitivos Idealizados, pois, para Lakoff (1987), "os MCI seria um conjunto complexo de frames distintos" (FERRARI, 2011, p. 53). O conceito de MCI será melhor detalhado a seguir:

um construto teórico desenvolvido por George Lakoff com objetivo de considerar os efeitos típicos encobertos pela Teoria dos Protótipos. Um MCI é uma representação mental relativamente estável que representa 'uma teoria' a respeito de algum aspecto de uma palavra e a quais palavras e outras unidades linguísticas podem ser relativizadas. A esse respeito, MCIs são similares à noção de frame, pois ambos relacionam-se a estruturas de conhecimento relativamente complexas (EVANS, 2007, p. 104). ${ }^{6}$

Para ilustrar o funcionamento de um MCI, Lakoff (1987) utiliza como exemplo a palavra "terça-feira". Para ele, "terça" pode ser definida em termos de um modelo idealizado, fundamentado no ciclo natural estabelecido pelo movimento do sol, que demarcaria o padrão de categorização para o fim de um dia e o início do próximo. Entretanto, esse ciclo, natural e observável empiricamente, é idealizado linearmente em horas, que, por sua vez, são idealizadas linearmente em dias. Segundo Lakoff (1987, p.68, grifos do autor), "no modelo idealizado, a semana é um todo com sete partes organizadas em uma sequência linear; cada parte é chamada de dia, e a terceira é chamada de terça"7. Portanto, de acordo com Lakoff (1987), a semana de sete dias não existe objetivamente na natureza, ela é uma criação humana.

Já a noção de Esquemas Imagéticos (doravante, EI) foi estabelecida por Johnson (1987). Segundo Johnson (1987, p.136) “Esquemas Imagéticos são, precisamente, estruturas da nossa

\footnotetext{
5 in some cases the area of experience on which a linguistic frame imposes order is a prototype

${ }^{6}$ a theoretical construct developed by George Lakoff in order to account for the typicality effects uncovered by Prototype Theory. An ICM is a relatively stable mental representation that represents a 'theory' about some aspect of the world and to which words and other linguistic units can be relativized. In this respect, ICMs are similar to the notion of a frame, since both relate to relatively complex knowledge structures

${ }^{7}$ In the idealized model, the week is a whole with seven parts organized in a linear sequence; each part is called a day, and the third is Tuesday.
} 
Volume 16 - Número 1 - jan/jul de 2021

experiência sensório-motora básica, pela qual encontramos um mundo que podemos entender e no qual podemos agir" das nossas interações que dão coerência e estrutura à nossa experiência"9 (JOHNSON, 1987, p. $18)$.

\subsection{Construal}

Langacker (2008) afirma, ao tratar sobre construal, que o sentido de uma expressão não é constituído, somente, pelo conteúdo que ela evoca. A forma por meio da qual o conteúdo é construído, é igualmente importante. De acordo com o autor, como parte de seu valor semântico convencional, toda estrutura simbólica constrói seu conteúdo de certa maneira. É muito difícil resistir à metáfora visual, na qual o conteúdo é ligado à cena e ao construal em um modo específico de visualizá-lo. Ele explica que a metáfora visual sugere um modo de classificar as muitas facetas do construal, se somente para propósitos explanatórios, pois ao visualizar uma cena, o que vemos, no momento da visualização, depende de quão próximos nós estamos desta cena, o que escolhemos olhar nela, em quais elementos nós prestamos mais atenção e de onde nós visualizamos essa cena. Segundo Evans (2007), o conceito de construal é clássico na Gramática Cognitiva langackeriana. Para o autor:

Construal [é] uma ideia central para a Gramática Cognitiva. Relaciona-se ao modo por meio do qual um usuário da língua escolhe para "empacotar" e "apresentar" uma representação conceptual codificável na língua, que, por sua vez, possui consequências para a representação conceptual que uma sentença evoca na mente do ouvinte. Essa representação é ativada pela escolha de determinado ajuste focal e, nesse sentido, organiza linguisticamente a cena de um modo específico. Dessa forma, o falante estabelece um único construal na cena. Por exemplo, a construção ativa focaliza atenção no AGENTE da ação (ex.: Max escondeu as chaves de Ana), enquanto a construção passiva focaliza a atenção no PACIENTE (ex.: as chaves de Ângela foram escondidas por Max). Cada uma dessas construções codifica convencionalmente um construal distinto ${ }^{10}$ (EVANS, 2007, p. 40-41, grifo da autora; inserção nossa).

Langacker (2008) estabelece que as classes amplas do fenômeno construal são: especificidade, focalização, proeminência e perspectiva. Neste artigo, focalizaremos, especificamente, a perspectiva, última classe tratada por Langacker (2008), pois dentro dela está o "ponto de vantagem" e os termos subjetividade e subjetificação, que serão tratados na próxima seção.

Para Langacker (2008), se a conceptualização, metaforicamente, corresponde à visualização de uma cena, a perspectiva corresponde ao "arranjo de visualização", o aspecto

\footnotetext{
${ }^{8}$ Image schemas are precisely these basic structures of our basic sensorimotor experience by which we encounter a world that we can understand and act within.

${ }^{9}(. .$.$) a recurring dynamic pattern of our perceptual interactions and motor programs that give coherence and$ structure to our experiences.

${ }^{10}$ Construal: an idea central to Cognitive Grammar. Relates to the way a language user chooses to 'package' and 'present' a conceptual representation as encoded in language, which in turn has consequences for the conceptual representation that the utterance evokes in the mind of the hearer. This is achieved by choosing a particular focal adjustment and thus linguistically 'organising' a scene in a specific way In so doing, the speaker imposes a unique construal upon that scene. For example, the active construction focuses attention upon the agent of an action (e.g. Max hid Angela's keys), while the passive construction focuses attention upon the patient (e.g. Angela's keys were hidden by Max). Each of these constructions conventionally encodes a distinct construal.
} 
mais óbvio é o "ponto de vantagem" assumido. Ele define "arranjo de visualização" como a relação entre os visualizadores e a situação que está sendo vista. Nessa concepção, os visualizadores são os que apreendem os sentidos das expressões linguísticas. Eles são, portanto: o falante e o ouvinte. Um "arranjo de visualização" específico, comum nas interações conversacionais do dia-a-dia, provavelmente possui status predefinido, sendo pressuposto ao menos que haja razão para afirmar o contrário. No arranjo predefinido, os interlocutores estão juntos em uma localização fixa, a partir da qual eles observam e descrevem as ocorrências atuais no mundo ao redor deles. Esse arranjo predefinido é evocado por tipos de sentenças, criadas por linguistas para propósitos ilustrativos, como: "a lâmpada está em cima da mesa" ou "João beijou Maria". Já o "ponto de vantagem" é definido, pelo autor, como a localização atual do falante e do ouvinte. Portanto, a mesma situação objetiva pode ser observada e descrita a partir de diferentes "pontos de vantagem", resultando em diferentes construals que podem ter consequências aparentes.

\subsection{Subjetividade e intersubjetividade}

Na perspectiva de Langacker (2008, 2006), os termos subjetividade e subjetificação pertencem ao "ponto de vantagem" (uma questão de construal, discutida na subseção anterior). De acordo com o autor, um dado sentido sempre comporta tanto a subjetividade quanto a objetividade como elementos constitutivos.

Langacker (2006, p.18, grifos do autor) utiliza os termos subjetivo e objetivo para aludir ao sujeito e ao objeto da concepção. Para ele, "uma entidade é tida como objetivamente construída na medida em que ela está em cena como um objeto de conceptualização explícito e focalizado" 11 e uma entidade é tida como "subjetivamente construída na medida em que ela está 'fora de cena' como um sujeito de concepção implícito, sem consciência" ${ }^{12}$. Sendo assim, está em questão, a assimetria inerente entre o conceptualizador e o que está sendo conceptualizado, entre a presença conceptualmente implícita e o alvo de conceptualização. $\mathrm{O}$ autor afirma que a assimetria é máxima quando o sujeito da concepção não possui qualquer autoconsciência, sendo totalmente absorvido na apreensão da situação em cena, e o objeto de conceptualização é saliente, bem definido e apreendido com alta precisão. Para ilustrar, de forma geral, os aspectos relacionados à aplicação da subjetividade versus objetividade, Langacker $(2008$, p. 77) descreve a seguinte situação referente à percepção visual:

Imagine você na plateia de um teatro, assistindo a uma peça arrebatadora. Toda sua atenção está direcionada ao palco e está focalizada mais especificamente no ator que está falando no momento. Sendo totalmente absorvido na peça, você dificilmente terá alguma consciência de si mesmo ou de suas circunstâncias imediatas. ${ }^{13}$

O arranjo visualizado maximiza, portanto, a assimetria entre o "visualizador" e "o que é visto", também chamado de "sujeito" e "objeto" da percepção. Conforme afirma o autor, nesse arranjo polarizado, no qual a assimetria do papel de visualizador é maximizada, o sujeito

\footnotetext{
${ }^{11}$ An entity is said to be objectively construed to the extent that it goes "onstage" as an explicit, focused object of conception

${ }^{12}$ Subjectively construed to the extent that it remains "offstage" as an implicit, unselfconscious subject of conception.

${ }^{13}$ Imagine yourself in the audience of a theater, watching a gripping play. All your attention is directed at the stage, and is focused more specifically on the actor presently speaking. Being totally absorbed in the play, you have hardly any awareness of yourself or your own immediate circumstances.
} 
Volume 16 - Número 1 - jan/jul de 2021

visualizado pode ser construído com máxima subjetividade e o objeto com máxima objetividade. Langacker (2006) ressalta que há uma questão de grau, mas que, em princípio, um sentido de uma expressão sempre incorpora a presença do conceptualizador que apreende e constrói a situação descrita.

Para introduzir a discussão da noção de intersubjetividade, Verhagen (2005) retoma a relação de construal proposta por Langacker (1987 apud VERHAGEN, 2005, p.5) e disposta a seguir como: "a relação entre o falante (ou ouvinte) e a situação que ele conceptualiza e retrata, envolvendo ajustes focais e imagéticos"14. Nessa definição, a relação de construal envolve, basicamente, um indivíduo (falante ou ouvinte) de um lado e a situação concebida de outro. Portanto, conforme afirma Verhagen, essa relação se aproxima bastante do "arranjo visualizado" (mencionado anteriormente nesta subseção).

A partir da proposta de Langacker, Verhagen (2005) sugere que, na verdade, a configuração de construal envolve um Ground $^{15}$. Sendo assim, qualquer evento de uso linguístico envolve dois conceptualizadores, o primeiro executando o papel de ser responsável pela sentença, e o segundo como aquele que interpreta a sentença de um modo específico. Nas conversações prototípicas face-a-face, esses papeis são totalmente preenchidos pelo falante e pelo destinatário, respectivamente, mas, conforme afirma o autor, papeis como esses são dados a partir de qualquer coisa que seja tomada como uma instância de uso linguístico, mesmo se os referentes para o primeiro e segundo papeis não forem conhecidos. A configuração de construal, sugerida por Verhagen (2005), pode ser representada graficamente na Figura 1:

Figura 1 - A configuração de construal e seus elementos básicos

O: Objeto de conceptualização

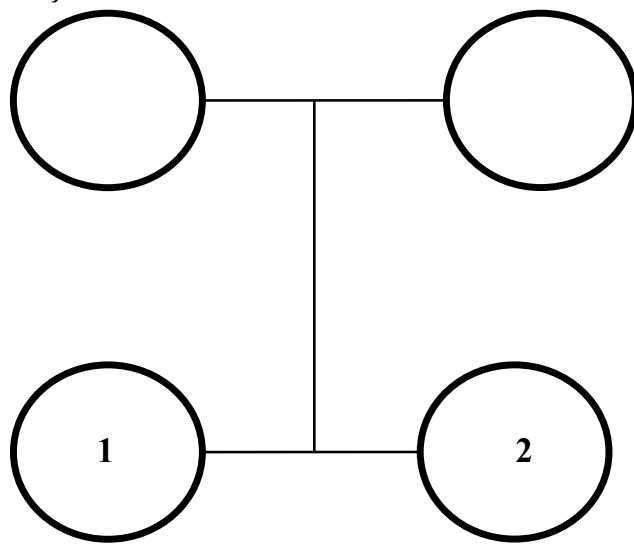

Fonte: Verhagen, 2005, p.07 (tradução nossa)

Segundo Verhagen (2005), nessa configuração de construal, representada na Figura 1, os sujeitos de conceptualização engajam-se na coordenação cognitiva por meio da sentença, com relação a algum objeto de conceptualização. Além disso, o Ground também contém o conhecimento que os conceptualizadores 1 e 2 compartilham mutualmente, incluindo modelos de cada um e da situação discursiva. Portanto, nessa concepção, o Ground é, essencialmente, um "Ground comum". O ponto da sentença linguística, em termos amplos, é que o primeiro conceptualizador convida o segundo a assistir, de maneira conjunta, a um objeto de conceptualização de algum modo específico e a atualizar esse Ground comum. O autor explica que, na representação gráfica, a relação de coordenação entre os dois conceptualizadores é

\footnotetext{
14 The relationship between a speaker (or hearer) and a situation that he conceptualizes and portrays, involving focal adjustments and imagery

15 Langacker 1987; 1990 (apud VEHAGEN, 2005, p. 06) define Ground como: o conjunto de um evento comunicativo, seus participantes e suas circunstâncias imediatas. (tradução nossa)
} 
indicada pela linha horizontal inferior e a relação de atenção compartilhada entre os conceptualizadores e o objeto de conceptualização é indicada pela linha vertical.

Verhagen (2005) cita casos extremos. De um lado, cita os casos que não envolvem nenhum elemento do Ground e são chamados de "maximamente objetivos". Conforme Langacker (apud VERHAGEN, 2005), casos como esses são relativamente raros e artificiais e podem ser ilustrados por nomes e verbos considerados isoladamente. Do outro lado, cita as expressões que são chamadas de "maximamente subjetivas", isto é, expressões que convencionalmente perfilam somente elementos do Ground e/ou a relação entre eles e nenhuma faceta do objeto de conceptualização. Exemplos de expressões puramente subjetivas, de acordo com o autor, são as interjeições, por exemplo: “Oi!", "Desculpe!”, "Ei!" etc. No entanto, Ferrari (2016) ressalta que as situações de máxima objetividade e máxima subjetividade constituem casos extremos em um continuum, uma vez que as posições intermediárias constituem a regra.

\section{Metáfora e gestos}

De acordo com Cienki (2008), se considerarmos os estudos tradicionais da metáfora, conforme os trabalhos de Lakoff e Johnson (1980), Johnson (1999) e Lakoff (1993), um dos princípios básicos é o de que a metáfora origina-se a partir de mapeamentos conceptuais entre domínios. Cienki (2008) afirma que, se a metáfora for baseada em mapeamentos de domínios cruzados, as palavras estabelecem apenas uma forma na qual a metáfora pode aparecer, uma vez que podemos encontrar expressões metafóricas em várias formas de comportamento humano, não restritas à língua.

Dentre as formas nas quais as metáforas podem aparecer estão os gestos. Cienki (2008) salienta que desde os anos 80 , tem crescido o número de pesquisas que focalizam nos gestos espontâneos que co-ocorrem com a fala, especialmente os gestos das mãos e dos antebraços. A respeito desses gestos, Kely, Church e Alibali (2017) questionam o que os torna tão interessantes? Para responder essa questão, os autores recorrem a Goldin-Meadow (2007 apud KELY, CHURCH E ALIBALI, 2017). A autora sugere que o gesto é uma "janela na mente". Isto é, que os gestos aparecem para refletir conteúdos na mente do falante, frequentemente, de um modo que reflete uma versão imagética do que está sendo falado. A autora acrescenta que os gestos podem oferecer, ainda, informações adicionais que não são capturadas na fala.

Para definir gesto, partimos do que é discutido por Kendon (2004). De acordo com o autor (2004), o gesto é definido como uma ação corporal visível que possui um papel em unidades de ação. O autor (2004) considera que o gesto prototípico passa por três fases, sendo elas: preparação, stroke (núcleo) e retração, sendo o núcleo, a fase que minimamente constitui um gesto. De acordo com a definição estabelecida por McNeill (1992), Cienki (2008) explica que o núcleo é, semanticamente, a fase do gesto que constitui o conteúdo. Além disso, Cienki (2008) afirma que essa fase é, também, a fase na qual há maior interesse para estabelecer a função do gesto como um todo.

Cienki (2008) salienta que os gestos diferem no grau de convencionalidade de formas e funções. Podemos considerar que nos gestos, assim como na metáfora, há uma gradiência. Essa gradiência vai desde os gestos que possuem significado fixo na cultura na qual eles são utilizados (emblemas), a gestos que são produzidos espontaneamente, nos quais o sentido é amplamente dependente do contexto. Como exemplos de emblemas, o autor cita o gesto de "OK", realizado com o polegar e o dedo indicador formando um anel ao tocar as pontas dos dedos, ou o gesto de "polegar para cima", para indicar uma avaliação positiva. Esse gesto é realizado com o polegar estendido verticalmente para cima e os demais dedos fechados em espiral. Em contraste aos emblemas, o autor cita os gestos espontâneos. Esses gestos são produzidos involuntariamente enquanto falamos, não possuem sentido pré-determinado e, 
Volume 16 - Número 1 - jan/jul de 2021

portanto, podem estabelecer um importante insight para o processo de formulação do pensamento enquanto falamos.

\section{Os modos de representação gestual}

Com base em Müller (1998a, 1998b, 2014), Cienki (2017) descreve os quatro modos de representação dos gestos manuais: "encenar", "corporificar", "segurar/moldar" (3D) e "desenhar" (2D). Descreveremos, brevemente, cada um desses modos de representação, conforme propostos mais recentemente por Cienki (2017, p.139, grifos nossos):

Encenar (enacting): a mão ou as mãos movem-se como se representassem engajamento em uma ação. Frequentemente, as mãos estão envolvidas "como se" manipulassem algo. Por exemplo: como se abrissem a tampa de uma garrafa ou como se escrevessem com uma caneta, embora o falante não esteja segurando uma garrafa ou uma caneta.

Corporificar (embodying): a mão coorporifica uma entidade que representa. Exemplos ocorrem quando alguém estende e move os dedos indicadores em alternância sobre uma superfície, simulando que eles são pernas de uma pessoa caminhando, ou quando alguém posiciona as duas mãos horizontalmente com as palmas pressionadas para representar dois pedaços de pão que fazem um sanduíche.

Segurar/moldar (holding/molding): as palmas das mãos encontram-se como se fossem adjacentes e conformam-se a uma entidade imagética, como se segurassem alguma coisa no ar (as mãos curvadas, com as palmas voltadas uma para a outra, como se segurassem uma bola) ou movem-se como se contornassem a superfície de um objeto.

Desenhar (drawing): a mão ou as mãos se movem como se desenhassem uma forma, frequentemente, com a ponta dos dedos constituindo a "zona ativa", movendo-se como se delineassem um traçado imagético da forma descrita. Por exemplo: o desenho de um retângulo com os dedos, ao se descrever a moldura de um quadro.

\section{Seleção do corpus}

As 6 (seis) ocorrências do verbo "cair" que selecionamos para análise estão abrigadas no Distributed Little Red Hen Lab, uma biblioteca de dados multimodais, composta por captações de gravação de programas de notícias e, eventualmente, de outros programas televisivos. A biblioteca contém milhões de horas de gravação de telejornais de vários países do mundo. A base de dados do Red Hen está hospedada e mantida, de forma segura, pela Universidade da Califórnia em Los Angeles (UCLA). $\mathrm{O}$ banco de dados possui, aproximadamente, 200 mil horas de notícias transmitidas pela internet, em um vasto número de línguas. Esse corpus revela a criatividade e variedade cultural da rede de notícias em todo o mundo. Ele inclui, em média, um bilhão de palavras em textos legendados, com marcação de data e hora, além de, em média, um bilhão de palavras transcritas. O Red Hen também adiciona, diariamente, milhares de horas de notícias televisivas.

Como critério de seleção das ocorrências analisadas, foram escolhidas seis ocorrências categorizadas como "menos prototípicas" ou "mais metafóricas" (c f. CIENKI, 2017), uma vez que pretendemos investigar a correlação dessas ocorrências com os Modos icônicos de Representação Gestual, bem como com a corporificação de Esquemas Imagéticos, via gestos, como também de metáforas conceptuais - e seus eventuais desdobramentos linguísticos via gestos e fala. Assim, torna-se possível avaliar a gradualidade das ocorrências. Além disso, em termos de construal, é possível discutir a instanciação multimodal de esquemas verbais 
Volume 16 - Número 1 - jan/jul de 2021

inicialmente pensados apenas para o conteúdo verbal, assim como a manifestação da subjetividade e da intersubjetividade no construal.

\section{Metodologia}

Desenvolvemos nossas análises baseando-nos no Sistema Linguístico de Notação Gestual (LASG) (BRESSEM et al., 2013) e nas Orientações para a Análise de Metáforas nos Gestos (MIG-G) (CIENKI, 2017). O Sistema Linguístico de Notação Gestual (Linguistic Annotation System for Gestures, doravante, LASG), proposto por Bressem e colaboradoras (2013), focaliza, inicialmente, a forma física dos gestos, promovendo uma categorização detalhada. Conforme as autoras (2013), o sistema é baseado em uma abordagem semiótica para os gestos, assumindo uma separação heurística entre forma, sentido e função gestual no processo analítico. Bressem e colaboradoras (2013, p. 1080) afirmam que o sistema de análise gestual proposto por elas se diferencia de outros sistemas existentes em três aspectos essenciais, pois esse sistema: "(i) concentra-se [em um primeiro momento] unicamente na descrição da forma dos gestos; (ii) propõe uma descrição de forma independente da fala; (iii) evita descrições de forma que incluem paráfrases de sentido" (BRESSEM et al., 2013, p.1080) ${ }^{16}$.

Nesse sentido, o sistema atende à notação da forma gestual, no que diz respeito à forma física, que inclui quatro parâmetros de descrição gestual, também utilizados pela Linguística da Língua de Sinais: (i) formato das mãos, (ii) orientação das mãos e palmas, (iii) direção e qualidade de movimento e (iv) posição do gesto no espaço.

Já as orientações para a identificação (ou não) de metáforas nos gestos seguem os seguintes passos, descritos por Cienki (2017):

1. Identificar os golpes gestuais. 2. Descrever as formas características de cada golpe. 3. Identificar se o gesto atende a alguma função referencial. Se sim, 4. Identificar o(s) modo(s) de representação. 5.Identificar o(s) referente(s) físico(s) retratados no(s) gesto(s) (o domínio fonte potencial). 6. Identificar o tópico contextual que está sendo referenciado (o potencial domínio alvo). 7. O tópico foi identificado por semelhança na experiência ao referente retratado por meio do gesto? Se sim, o gesto pode ser identificado como utilizado metaforicamente por meio de um mapeamento no qual o tópico (Domínioalvo) está sendo conectado ao referente retratado (Domínio-fonte). (CIENKI, 2017, p. 136$)^{17}$

O autor faz uma ressalva de que os dois primeiros passos são executados mais adequadamente com o som do vídeo desligado, com o intuito de ajudar o analista a manter o foco nas formas gestuais visíveis, sem nenhuma distração ou influência da fala associada. Essa mesma orientação, de observar as formas gestuais isoladamente, correspondem ao primeiro bloco de análise do LASG.

\footnotetext{
16 (i) It concentrates solely on a form description of gestures; (ii) It proposes a form description independent of speech (iii) It avoids gestural form description including paraphrases of meaning

${ }^{17} 1$. Identify the gesture strokes. 2. Describe the four form features of each stroke. 3. Identify if the gesture serves any referential function. If so, 4. Identify the mode(s) of representation. 5. Identify the physical referent(s) depicted in the gesture(s) (the potential Source domain). 6. Identify the contextual topic being referenced (the potential Target domain). 7. Is the topic being identified via a resemblance in experience to the referent depicted via the gesture? If so, the gesture can be identified as metaphorically used via the mapping that the topic [This Target Domain] is being likened to the referent depicted [This Source Domain].
} 
Volume 16 - Número 1 - jan/jul de 2021

\section{Análise das ocorrências}

A análise da ocorrência 1, a partir da representação multimodal, está disposta na Figura 2:

Figura 2 - Representação multimodal da ocorrência 1

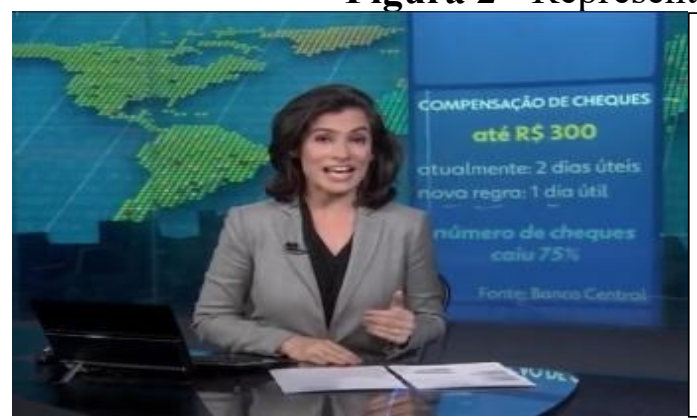

"O prazo para compensação de cheques de até 300 reais vai cair de dois pra um dia útil"

Polegar estendido, demais dedos dobrados, palma horizontal, movimento em direção ao corpo, preciso, distância curta em relação ao corpo.

Fonte: Dados do Red Hen

$\mathrm{Na}$ análise do núcleo gestual que co-ocorre com o discurso nessa ocorrência do verbo "cair", categorizamos o modo de representação icônico retratado no gesto como Modo de Representação "Holding/Molding" (Segurar/Moldar -3D), pois é "como se" a falante estivesse delimitando barreiras, que correspondem, então, ao referente físico retratado no gesto. Esse referente, que co-ocorre com o tópico contextual, referenciado na fala, "vai cair", instancia o Esquema Imagético TRAJETÓRIA. Sendo assim, categorizamos a ocorrência como menos prototípica ou mais metafórica, pois o referente físico retratado no gesto contrasta com o tópico contextual referenciado "vai cair" que não remete a queda de um objeto físico, mas sim a queda do prazo. Além disso, é importante salientar que nessa ocorrência, assim como nas demais analisadas nesse artigo, não há um encontro face a face, mas mesmo assim, a intersubjetividade existe, uma vez que, conforme Verhagen (2005), mesmo na ausência de um destinatário atual, o falante, nesse caso, a apresentadora do Jornal Nacional, está comprometido com a proposição de que sua fala (na unidade gesto fala) é, em princípio, interpretada por outra pessoa (um interlocutor imediato ausente na cena, que nesse caso, se configura como o telespectador do Jornal Nacional) que compartilha o conhecimento dessas convenções. Portanto, a estrutura conceptual apresentada por Verhagen (2005) na figura 1 (c.f. seção 2.3, referente à subjetividade e intersubjetividade) é inerente também a casos como o dessa ocorrência (a apresentação de um telejornal).

A análise da ocorrência 2, a partir da representação multimodal, está disposta na Figura 3:

Figura 3 - Representação multimodal da ocorrência 2

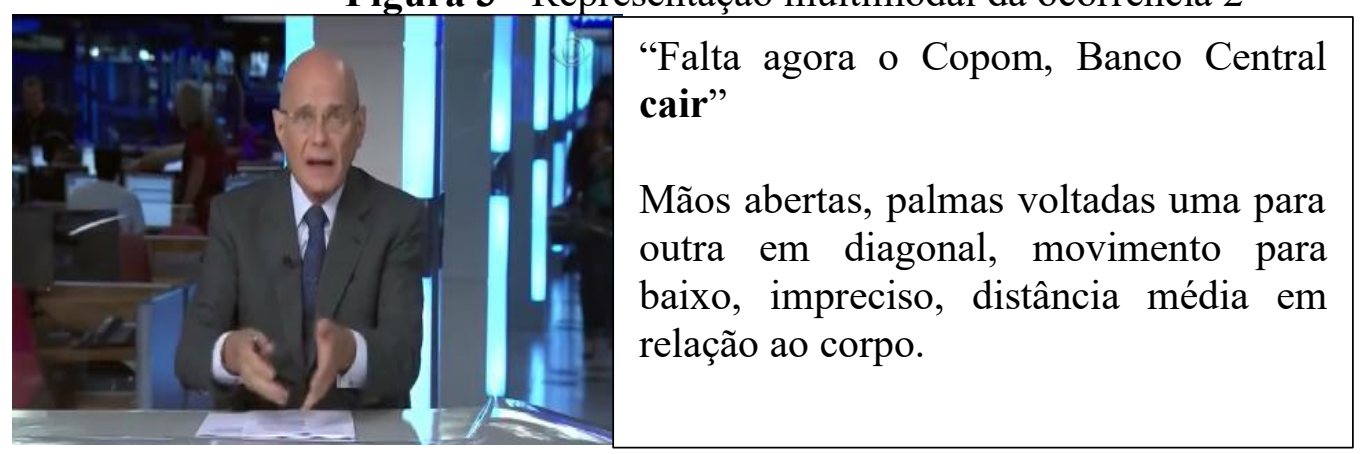




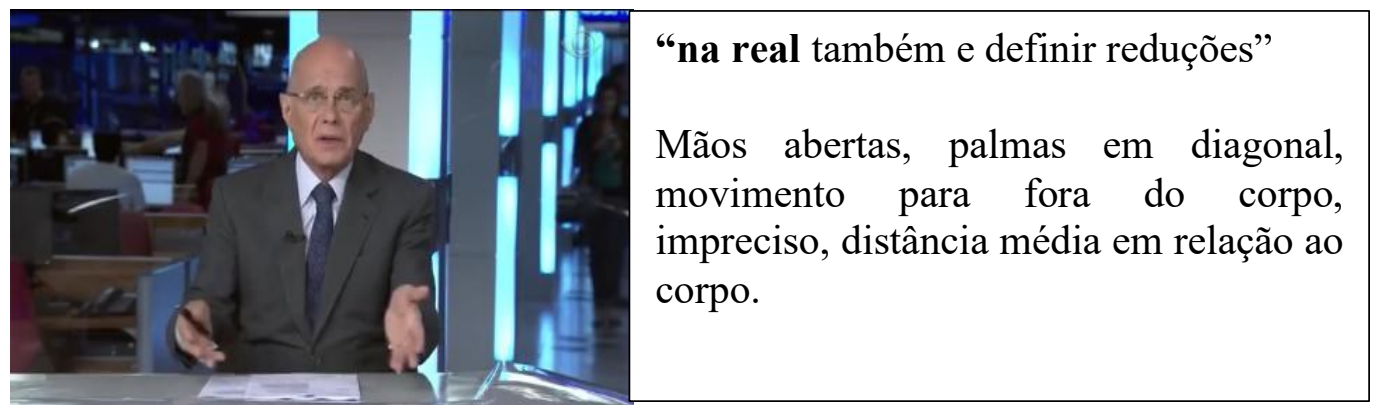

Fonte: Dados do Red Hen

$\mathrm{Na}$ análise do primeiro núcleo gestual que co-ocorre com o discurso nessa ocorrência do verbo "cair", categorizamos o modo de representação icônico retratado no gesto como Modo de Representação "Enacting" (Encenar), pois é "como se" o falante estivesse encenando a queda de um objeto. Sendo assim, por meio do referente físico retratado no gesto, que contrasta com o tópico contextual referenciado, evidencia-se a ocorrência do Esquema Imagético "OBJETO" que instancia a metáfora conceptual "IDEIAS SÃO OBJETOS” (MCNELL; CASELL; LEVY, 1993). Além disso, ao considerar o tópico contextual "cair na real", identificamos a ocorrência de uma expressão idiomática com sentido metafórico. Sendo assim, categorizamos essa ocorrência como possuindo um grau de metaforicidade intermediário, uma vez que "cair na real" é uma expressão idiomática e, portanto, extremamente convencionalizada.

A análise da ocorrência 3, a partir da representação multimodal, está disposta na Figura 4:

Figura 4 - Representação multimodal da ocorrência 3

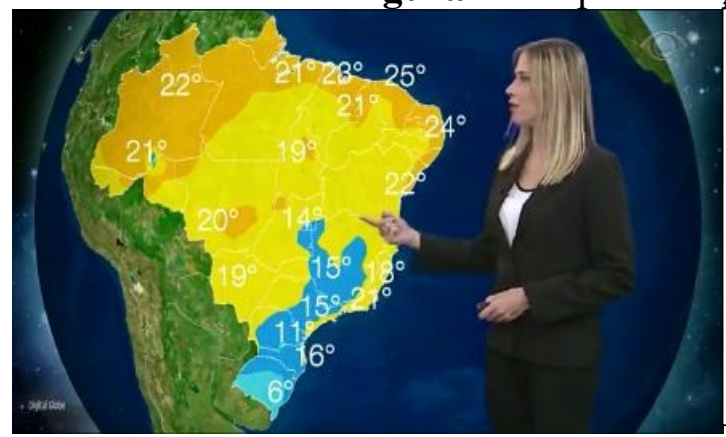

A frente fria avança vem também a massa de ar de origem polar, então, a temperatura já começa a cair e vai cair ainda mais.

Dedo indicador estendido, palma em diagonal, movimento para a direita, distância média em relação ao corpo.

Fonte: Dados do Red Hen

$\mathrm{Na}$ análise do núcleo gestual que co-ocorre com essa ocorrência do verbo "cair", categorizamos o modo de representação icônico retratado no gesto como "Desenhar (Drawing) - (2D)", pois é "como se" a falante estivesse desenhando um gráfico. Esse referente co-ocorre com o tópico contextual referenciado na fala: "vai cair ainda mais". Essa ocorrência instancia a metáfora orientacional "MENOS É PARA BAIXO" ("LESS IS DOWN") (LAKOFF; JOHNSON, 1980) e o Esquema Imagético TRAJETÓRIA (JOHNSON, 1987). Sendo assim, categorizamos essa ocorrência do verbo "cair" como mais metafórica ou menos prototípica. Além disso, nessa ocorrência, é importante retomar o esquema verbal proposto por Langacker (2008), pois, conforme podemos observar, a fotografia do núcleo gestual retrata uma relação simples (simplex): uma única configuração na qual o gesto ocupa uma localização específica, mas o evento global, nesse caso, o referente físico retratado no gesto que co-ocorre com o tópico contextual referenciado: "vai cair ainda mais", inclui as várias localizações do gesto e, portanto, é complexo (complex), pois o gesto dinâmico é composto por vários momentos específicos que 
podem ser retratados, ou seja, pela soma das relações simples (simplex) que constituem as relações complexas (complex).

É também nesse sentido que o autor argumenta que as relações componentes - referidas como estados - não são examinadas individualmente, nem separadamente no nível de percepção consciente. Ao invés disso, o evento é conceptualizado como integralmente desenvolvido. Portanto, o telespectador conceptualiza o evento de forma global na integração gesto-fala.

A análise da ocorrência 4, a partir da representação multimodal, está disposta na Figura 5:

Figura 5 - Representação multimodal da ocorrência 4

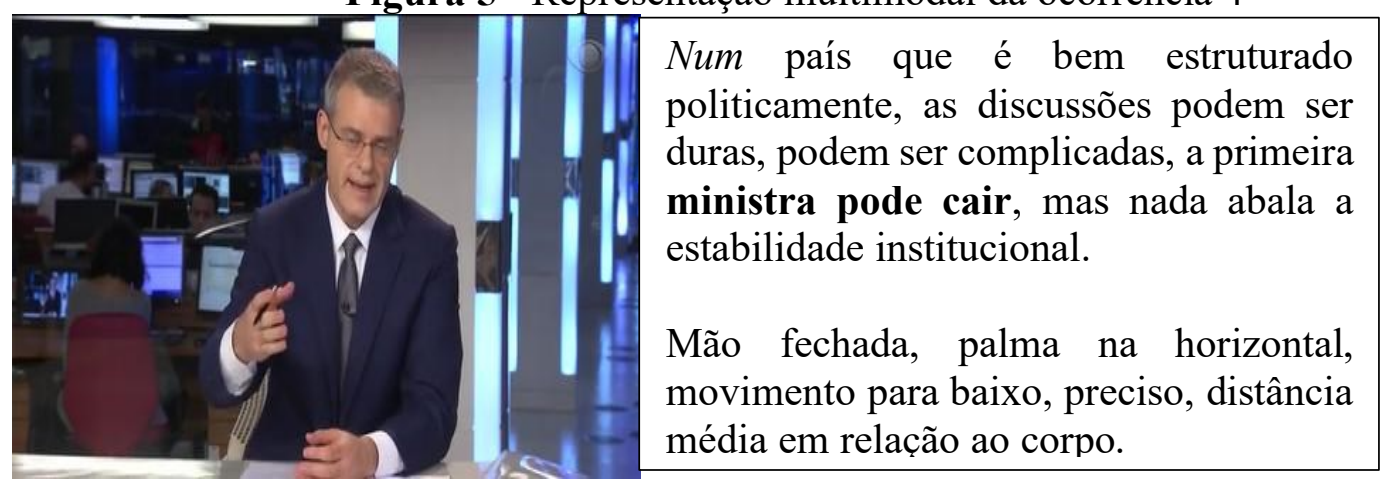

Fonte: Dados do Red Hen

$\mathrm{Na}$ análise do núcleo gestual que co-ocorre com essa ocorrência do verbo "cair", categorizamos o modo de representação icônico retratado no gesto como Modo de Representação "Enacting" (Encenar), pois é "como se" o falante estivesse encenando uma trajetória descendente, por meio de um movimento sutil, que corresponde ao referente físico retratado no gesto. Sendo assim, esse referente, que co-ocorre com o tópico contextual referenciado na fala "pode cair", instancia o Esquema Imagético TRAJETóRIA. Portanto, categorizamos a ocorrência como menos prototípica ou mais metafórica, pois o referente físico retratado no gesto contrasta com o tópico contextual referenciado e o tópico contextual referenciado "pode cair" não remete à queda de algo físico, mas sim à possibilidade de "queda" da primeira ministra, isto é, a possível desocupação do cargo.

A análise da ocorrência 5, a partir da representação multimodal, está disposta na Figura 6:

Figura 6 - Representação multimodal da ocorrência 5

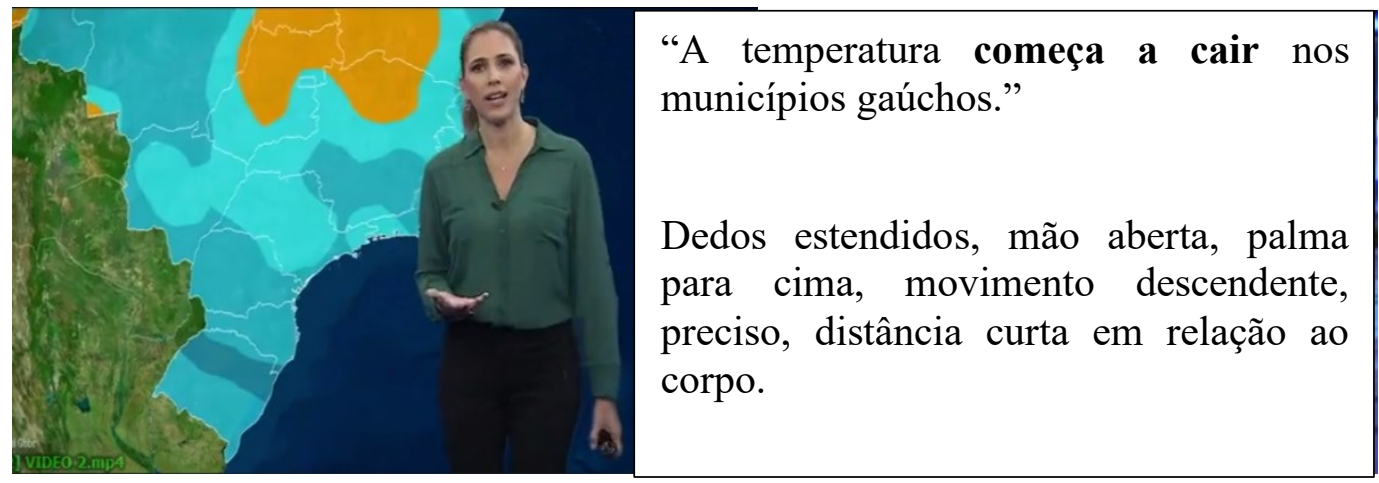

Fonte: Dados do Red Hen 
Ao considerar a ocorrência 5, categorizamos o modo de representação icônico do gesto como "Encenar" (Enacting), uma vez que apresentadora encena uma queda por meio de um movimento descendente. Essa ocorrência instancia a metáfora orientacional "MENOS É PARA BAIXO" ("LESS IS DOWN") (LAKOFF; JOHNSON, 1980), pois o gesto co-ocorre com o tópico contextual "começa a cair" e, instancia também, o Esquema Imagético TRAJETÓRIA (JOHNSON, 1987). Desse modo, assim como na ocorrência 3, categorizamos a ocorrência do verbo "cair" como mais metafórica ou menos prototípica.

Por fim, a análise da ocorrência 6, a partir da representação multimodal, está disposta na Figura 7:

Figura 7 - Representação multimodal da ocorrência 6

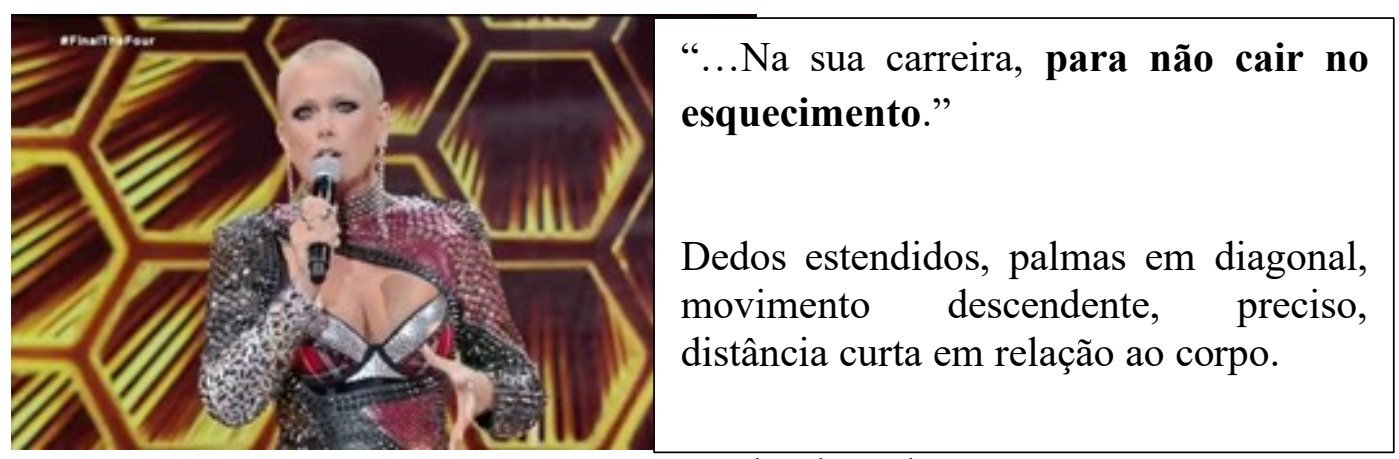

Fonte: Dados do Red Hen

No que diz respeito à ocorrência 6 , categorizamos o modo de representação icônico retratado no gesto como "Encenar" (Enacting), pois a falante encena, também por meio de um movimento descendente, uma queda. O referente, ao co-ocorrer com o tópico contextual "cair no esquecimento", instancia o Esquema Imagético TRAJETÓRIA. Nesse sentido, categorizamos a ocorrência como menos prototípica ou mais metafórica, pois o referente "cair no esquecimento" não se refere à queda de um objeto físico, mas sim ao ostracismo da carreira de um personagem da interação.

\section{Considerações finais}

Por meio das análises realizadas, notamos que as seis ocorrências do verbo "cair", categorizadas como mais metafóricas ou menos prototípicas, apresentam graus diferentes de metaforicidade. Destacamos que os gestos dessas seis ocorrências foram identificados como mais metafóricos, por meio de um mapeamento no qual o tópico (Domínio-alvo), contido no discurso verbal (na fala), está sendo conectado ao referente retratado (Domínio-Fonte), representado ou apontado pelo gesto, conforme estabelece o passo 7, descrito por Cienki (2017), nas Orientações para a Análise de Metáforas nos Gestos (MIG-G). Assim, consideramos que as metáforas conceptuais não estão restritas à fala (ou à escrita) e podem ser representadas e corporificadas nos gestos. No entanto, apesar de todas as ocorrências terem sido categorizadas como metafóricas, cada uma funcionou de forma distinta. Elas apresentaram diferentes Modos de Representação: "Holding/Molding" (Segurar/Moldar -3D), "Enacting" (Encenar)" e "Desenhar (Drawing)" e diferentes referentes físicos retratados no gesto: delimitar barreiras, objeto e desenhar um gráfico.

Além disso, as ocorrências 1, 4 e 6 instanciaram o Esquema Imagético TRAJETÓRIA, a ocorrência 2 instanciou o Esquema Imagético OBJETO e a metáfora conceptual "IDEIAS SÃO OBJETOS” e uma metáfora linguística desdobrada em Metáfora Conceptual. Já as ocorrências 3 
Volume 16 - Número 1 - jan/jul de 2021

e 5 instanciaram a metáfora orientacional "MENOS É PARA BAIXO" (LESS IS DOWN) e o Esquema Imagético TRAJETÓRIA. De modo mais específico, retomamos, a partir da análise da ocorrência 3, o esquema verbal proposto por Langacker (2008) e aplicamos empiricamente: o autor explica o desenvolvimento de um evento através do tempo, considerando a posição de um objeto físico no espaço, e nessa ocorrência, observamos o desenho de um gráfico (referente físico retratado no gesto) por meio das várias localizações do gesto no tempo e da co-ocorrência com o tópico contextual referenciado.

Por fim, é importante salientar, em consonância com a proposta de Verhagen (2005), que em todas as ocorrências, mesmo sem haver um encontro face a face, houve manifestação da intersubjetividade, pois os falantes, na integração gesto-fala, pressupõem os telespectadores (interlocutores imediatos ausentes na cena).

\section{Referências}

BRESSEM, J. et al. A linguistic perspective on the notation of form features in gestures. In: MÜLLER, C.; CIENKI, A.; FRICKE, E.; LADEWIG, S.; MCNEILL, D.; TESSENDORF, S. (Eds.), Body - Language - Communication. v. 1. Berlin/Amsterdam/New York:De Gruyter Mouton, 2013, p. 1079-1098.

CIENKI, A. Why study metaphor and gesture? In: CIENKI, Alan; MÜLLER, Cornelia (eds.), Metaphor and Gesture. Amsterdam/Philadelphia: John Benjamins. 2008, p. 5 - 25.

CIENKI, A. Analysing metaphor in gesture: A set of metaphor identification guidelines for gesture (MIG-G). In: E. Semino, \& Z. Demjén (Eds.), The Routledge handbook of metaphor and language. London: Routledge, 2017, p. 131-147.

EVANS, V. The Cognitive Linguistics Reader. BENJAMIN K. Bergen e JÖRG Zinken (Eds.).Londres: Equinox Publishing Co, 2007, p. 40-41.

FERRARI, L. Introdução à Linguística Cognitiva. São Paulo: Contexto, 2011.

FERRARI, L. Subjetividade e intersubjetividade na Gramática Cognitiva. In: ALVARO, T. P.; FERRARI, L. (Orgs.). Linguística Cognitiva: da linguagem aos bastidores da mente. Campos dos Goytacazes: Ed.: Brasil Multicultural, 2016, p. 64-83.

FILLMORE, C. J. An alternative to checklist theories of meaning. Berkeley Linguistics Society, 1975, p.123-131.

HOSTETTER, A.; ALIBALI, M. Visible embodiment: Gestures as simulated action. Psychonomic Bulletin \& Review, 15 (3), 2008, p. 495-514.

JOHNSON, M. The body in the mind: The bodily basis of meaning, imagination, and reason. Chicago, London: The University of Chicago Press, 1987.

KELLY, S. D., ALIBALI, M. W., \& CHURCH, R. B. Understanding gesture: Description, mechanism, and function. In R. B. CHURCH, M. W. ALIBALI \& S. D. KELLY (Eds.). Why gesture? How the hands function in speaking, thinking and communicating. John Benjamins Publishing: Amsterdam, 2017 p. 3-10.

KENDON, A. Gesture: visible action as utterance. Cambridge: Cambridge University Press, 2004.

LAKOFF, G. Women, fire, and dangerous things: What categories reveal about the mind. Chicago, London: The University of Chicago Press, 1987.

LAKOFF, G. \& JOHNSON, M. Metaphors we live by. Chicago/London: The University of Chicago Press, 1980.

LANGACKER, R. W. Cognitive Grammar: A Basic Introduction. New York: Oxford University Press, 2008. 
Volume 16 - Número 1 - jan/jul de 2021

LANGACKER, R. W. Subjectification, grammaticalization, and conceptual archetypes. In: Athanasiadou, Canakis \& Cornillie (eds.). Subjectification: Various Paths to Subjectivity. Belin/New York: Mounton de Gruyter, p.17-40, 2006.

MCNEILL, D.; CASSELL, J; LEVY, E.T. Abstract deixis. Semiotica, v. 95, n.1. Berlin: Walter de Gruyter, 1993, p. 5-19.

VERHAGEN, A. Constructions of intersubjectivity: Discourse, Syntax and Cognition. Oxford University Press, 2005. 